\title{
Scrub typhus: risks, diagnostic issues, and management challenges
}

\author{
This article was published in the following Dove Press journal: \\ Research and Reports in Tropical Medicine \\ 7 August 2017 \\ Number of times this article has been viewed
}

\author{
John Antony Jude Prakash \\ Department of Clinical Microbiology, \\ Christian Medical College, Vellore, \\ Tamil Nadu, India
}

\begin{abstract}
Scrub typhus is an acute febrile illness in the "tsutsugamushi triangle", transmitted by chiggers that can be treated effectively if detected early. Laboratory testing, including molecular and serological assays, is needed for confirming the diagnosis, especially in the absence of the pathognomonic eschar. In this review, factors that play a role in disease occurrence and clinical clues for diagnosis, in addition to risk factors contributing to disease severity, including mortality, are discussed in detail. Moreover, issues related to diagnostic assays, treatment, and mixed infections are also enumerated and described.
\end{abstract}

Keywords: Orientia tsutsugamushi, disease severity, mortality predictors, diagnosis, coinfections, treatment

\section{Introduction}

Scrub typhus is a vector-borne zoonosis endemic in South Asia, Southeast Asia, East Asia, the Pacific Islands, and Northern Australia (the "tsutsugamushi triangle"), with reports of similar infections from Africa, the Middle East, and South America. ${ }^{1}$ This infection is caused by Orientia tsutsugamushi, which is transmitted to humans by the bite of infected chiggers (larvae) of trombiculid mites. ${ }^{2}$ The name "tsutsugamushi disease" was given by Hashimoto in $1810 .^{3}$ The tsutsugamushi triangle is home to more than half the world's population, ${ }^{4}$ with 2 billion at risk and 1 million cases of scrub typhus occurring per year. ${ }^{5}$ Clinical manifestations range from asymptomatic to severe disease. The mortality rate varies and can be as high $50 \%,{ }^{6}$ such that the mortality among 1 million infections in a single year is likely enormous. ${ }^{7}$ This is because the organism responsible affects the vascular endothelium and mononuclear macrophages. Therefore, all organs, including the lungs, liver, kidneys, and central nervous system, can be affected. ${ }^{8}$ Misdiagnosis and underdiagnosis is also known to occur due to lack of availability of diagnostic tests and the aspecific nature of symptoms, especially when the characteristic eschar is not present. ${ }^{7,9-11}$

Scrub typhus is not transmitted directly from person to person; it is only transmitted by the bites of vectors. ${ }^{12}$ The vector responsible is the chigger of the trombiculid mite belonging to the genus Leptotrombidium, but recently newer vector genera have been discovered that are capable of transmitting this agent. Tilak et al reported that Schoengastiella ligula (northeast India) transmitted O. tsutsugamushi in tea-garden workers, ${ }^{13}$ while Lee et al discovered this agent could be transmitted by Euschoengastia koreaensis in South Korea. ${ }^{14}$ Knowledge of the vector, including species, distribution, density, and habitats, is important to understand the epidemiology of scrub typhus in
Correspondence: John Antony Jude Prakash

Department of Clinical Microbiology, Christian Medical College, Vellore, Ida Scudder Road, Tamil Nadu 632004, India Tel +9l 4162282588

Email prakjaj@cmcvellore.ac.in 
a given area or region. ${ }^{15}$ Vector activity is related to temperature, rainfall (climate), land use (ecology), and various socioeconomic factors. ${ }^{4,8,15-17}$ An increase in vector density contributes to increased transmission, due to more humans being bitten by infected chiggers.

O. tsutsugamushi serotype distribution varies from region to region in the tsutsugamushi triangle, and strain types are identified by sequencing the $56 \mathrm{kDa}$ gene. ${ }^{18-20}$ In South Korea, the Boryong serotype is predominantly encountered, the Karp and Gilliam serotypes are common in Taiwan, and the Gilliam serotype is prevalent in China. ${ }^{18}$ In India, based on a $56 \mathrm{kDa}$ analysis, strains similar to Kato and Karp are common, whereas in Japan Kato, Karp, Gilliam, Kawasaki, and Kuroki types are observed. ${ }^{19}$

Scrub typhus without the eschar is a febrile illness without any evidence of localization, and is hence termed "acute undifferentiated fever". ${ }^{21-24}$ This illness is thus clinically indistinguishable from malaria, dengue fever, other rickettsioses, leptospirosis, and enteric fever, which are common causes of acute undifferentiated fever in the Asia-Pacific region. ${ }^{10,22,23,25-29}$ In this review, factors describing populations at risk, severity predictors, clinical clues, diagnostic assays, coinfections observed, and drugs available for treatment of scrub typhus are described.

\section{Risk factors for acquiring scrub typhus}

The abundance of the chigger of the trombiculid mite, which is the vector for scrub typhus, determines the chance of acquiring scrub typhus, which in turn determines the prevalence of scrub typhus in a given region. ${ }^{4}$ There is always a spurt of cases during certain seasons in the endemic areas described, and this varies from country to country and is dependent on the climate ${ }^{1}$ and environment. Additionally, within a country, certain regions show increased prevalence.

Chiggers are abundant in locales with high relative humidity $(60 \%-85 \%)$, low temperature $\left(20^{\circ} \mathrm{C}-30^{\circ} \mathrm{C}\right)$, low incidence of sunlight, and a dense substrate-vegetative canopy. ${ }^{2,30,31}$ As such, they are found in great numbers in forest clearings, riverbanks, and grassy regions. Humans acquire scrub typhus on exposure to infected larvae (chiggers) of trombiculid mites. The density of chiggers of Leptotrombidium pallidum and L. scutellare is very high from September to November in South Korea, with a consequent rise in scrub typhus in humans. This provides evidence that an increase in chigger density of the vector species is responsible for the high seasonal prevalence in endemic areas. ${ }^{17}$ This variation in chigger activity gives rise to the seasonality of scrub typhus.
Peak prevalence in South Korea occurs in autumn (September-November), in Japan increased cases are observed in autumn and winter, in north China (Shandong) in September-November, and in south China in June-September. In south India, scrub-typhus cases occur mostly in the cooler months (August-January), while in Southeast Asia scrub-typhus cases are highest in July-November. ${ }^{32}$ Incidence of scrub typhus can vary from country to country and also region in large countries like India and China. It has been reported that each $1^{\circ} \mathrm{C}$ and $1 \%$ change in temperature can cause an increase in incidence, ${ }^{16}$ as evidenced by a $15 \%$ rise in scrub-typhus cases in Guangzhou, China. ${ }^{8}$

In addition to temperature, secondary vegetation and rainfall also increase the incidence of scrub typhus. ${ }^{33}$ Occupational risk is higher in farmers (aged 50-69 years), females, ${ }^{6}$ and those working in vegetable fields, harvesting in autumn, ${ }^{34}$ and rural highlands. ${ }^{35}$ In a study by Kweon et al, outdoor activities like resting on a grass field without a mat, working in short sleeves and bare hands, and defecating and/or urinating outdoors while squatting increased risk for scrub typhus. ${ }^{12}$ In a case-control study from South Korea, individuals engaged in fruit farming, gathering chestnuts, and taking breaks in areas adjacent to agricultural operations had an increased risk of contracting scrub typhus compared to controls. The authors opined that providing a health-education program would lower the risk in these individuals and similar groups. ${ }^{36}$ Land use is another determinant, as scrub-typhus incidence increases when forest lands are converted to fields, palm oil, and rubber plantations, ${ }^{2}$ and also when urbanization occurs. ${ }^{36}$

\section{Clinical clues favoring a diagnosis of scrub typhus \\ Presence of eschars}

The presence of eschars is considered pathognomonic. It has been reported that eschar incidence varies from $7 \%$ to $97 \%$ in endemic areas ${ }^{5}$ and is painless. ${ }^{37}$ Eschars are often found in covered areas of the body, such as the groin, axilla, chest, and lower back, including the buttocks., ${ }^{9,10,38-40}$ Recently, there have been reports of multiple eschars ${ }^{41,42}$ and atypical eschars, ${ }^{43}$ which were punched-out ulcers with slough. This could also be due to the original eschar scab being removed by scratching ${ }^{44}$ or falling away, especially during bathing. This seems plausible, because the eschar appears at the chigger-bite site a few days before the onset of symptoms. ${ }^{37}$ Therefore, a thorough examination becomes necessary and improves eschar detection, leading in turn to improvement in the diagnosis of scrub typhus in a clinical setting. This has been observed at our center: eschar incidence improved from 
$<10 \%$ in $2003^{45}$ to $55 \%$ in $2013 .{ }^{46}$ Eschars of scrub typhus appear a few days after at chigger-bite sites, before the disease manifests. The eschar is painless and consists of a black scab, with an erythematous halo and minimal edema. ${ }^{44,47}$ Detection of eschars is dependent not only on the clinical experience of the examining physician but is also influenced by skin color (eschars are more easily seen on the fair-skinned than the dark-complexioned) and also on the thoroughness of the physical examination. ${ }^{48}$ The differentials for a scrub-typhus eschar include insect bites (including spider bites) and posttraumatic scabs ${ }^{49}$ which can all be ruled out with a little patience and perseverance. The eschar of anthrax, though painless, is surrounded by extensive or marked edema that is gelatinous and stretches the skin, and is often preceded by a pruritic papule. ${ }^{50,51}$ Table 1 gives a summary of clinical and laboratory findings favoring or not favoring a diagnosis of scrub typhus. ${ }^{23,25,28,52-58}$

\section{Use of clinical prediction rules}

As given in Table 1, a few clinical clues other than eschars are available for suspecting or diagnosing scrub typhus in the clinic or at the bedside. It is to be noted that even at a referral hospital in endemic countries, the diagnosis of scrub typhus is usually based on the clinical findings. ${ }^{54}$ As definitive diagnosis requires laboratory testing, clinical prediction rules have been tried. Chen et al observed a $100 \%$ negative predictive value for clinical criteria combining the presence of eschars, atypical lymphocytes in peripheral blood smear, and contact history. ${ }^{59} \mathrm{~A}$ clinical rule formulated for scrub typhus by Jung et al uses five predictors with a maximum score of 8 points. The scoring criteria include age $\geq 65$ years ( 2 points), recent history of fieldwork/outdoor activities (1 point), onset of illness during an outbreak period of scrub typhus (2 points), myalgia ( 1 point), and eschars ( 2 points). A score below 3 rules out scrub typhus, while $100 \%$ sensitivity was observed for a score $\geq 3$. the authors felt that this could be used for selecting patients for empirical therapy in resource-poor situations or for performing specific laboratory tests. ${ }^{23}$ Similarly, Siriwongpan et al devised and validated a clinical risk scoring system using a set of 526 patients with scrub typhus based on the World Health Organization (WHO) case definition. ${ }^{60-62}$

\section{Risk factors determining severity and outcome in scrub typhus Severity of disease based on genotype}

The severity of scrub typhus varies considerably, which might correlate with the virulence of the particular $O$. tsutsugamushi strain responsible for the infection. There is evidence that frequency of eschars and rash in scrub typhus is dependent on the infecting genotype. South Korean individuals with the Boryong genotype have significantly higher incidence (97\%) of eschars and skin rash compared to $74 \%$ with the Karp genotype ${ }^{63}$ Karp genotypes (summer scrub typhus, isolated in Guangdong, Fujian, Hainan provinces in southern China) were found to be more virulent and caused more severe disease than Kawasaki genotypes (autumn-winter scrub typhus) isolated in Shandong and northern Jiangsu provinces in northern China. ${ }^{48}$ Eschar presence was not significant in severe and nonsevere scrub typhus. ${ }^{64}$

\section{Clinical and laboratory parameters predicting severity in scrub typhus}

Patients with possible scrub typhus with low body temperature, rapid pulse rate, presence of crepitation, low percentage of lymphocytes, low serum albumin, elevated aspartate aminotransferase, elevated serum creatinine, and positive urine albumin should be monitored closely for severity progression. ${ }^{60}$ Tables 2 and 3 provide a summary of the significant features predicting severity and outcome of scrub typhus. Parameters that show very significant $P$-values $(0.01)$ by multivariate logistic regression analysis have been included in the tables. In a meta-analysis of 89 studies $(19,644$ patients with scrub typhus), fatal outcome was reported in 2,488 patients, with an overall mortality of $12.7 \%$. Though increasing age

Table I Parameters compatible and incompatible with a diagnosis of scrub typhus $(P<0.0 \mathrm{I})$

\begin{tabular}{ll}
\hline Supporting a diagnosis of scrub typhus & Against a diagnosis of scrub typhus (usually diagnosed) \\
\hline Eschar & Bone pain (dengue) \\
Regional lymphadenopathy & Bleeding manifestations (dengue) \\
Total fever $\geq 8$ days & Loose stools (enteric fever) \\
CRP $>32 \mathrm{mg} / \mathrm{L}$ & White blood-cell counts $<5,000 / \mathrm{mm}^{3}$ (dengue) \\
ALT/AST $>$ I & Platelets $<50,000 / \mathrm{mm}^{3}$ (dengue) \\
Defervescence within 48-72 hours of specific therapy & Bilirubin $>2 \mathrm{mg} / \mathrm{dL}$ (malaria, hepatitis A) \\
& AST $>500 \mathrm{U} / \mathrm{L}$ (dengue) \\
& $\mathrm{ALT}<100 \mathrm{U} / \mathrm{L}$ (malaria) \\
& $\mathrm{ALT}>500 \mathrm{U} / \mathrm{L}$ (hepatitis A) \\
\hline
\end{tabular}


Table 2 Predictors of mortality in patients diagnosed with scrub typhus $(P<0.0 \mathrm{I})$

\begin{tabular}{|c|c|c|c|}
\hline Parameter & Significant value & OR $(95 \% \mathrm{Cl})$ & Study \\
\hline Age & $>65$ years & $14.5(1.3-166.4)$ & Thipmontree et $\mathrm{al}^{66}$ \\
\hline Creatinine & $>1.5$ times normal & $12.8(1.8-92.1)$ & \\
\hline Total bilirubin & $>3 \mathrm{mg} / \mathrm{dL}$ & $24.8(2.1-286.6)$ & \\
\hline Hemoglobin & $\leq 10 \mathrm{~g} / \mathrm{dL}$ & $32.1(2.6-393.8)$ & Park et $\mathrm{a}^{67}$ \\
\hline Inotropic support & $\mathrm{BP}<90 \mathrm{mmHg}$ & $10.1(4.5-22.9)$ & Varghese et $a^{68}$ \\
\hline Creatinine & $>2 \mathrm{mg} / \mathrm{dL}$ & $3.5(1.7-7.1)$ & \\
\hline CNS dysfunction & - & $6(2.8-12.8)$ & \\
\hline Metabolic acidosis & Venous $\mathrm{HCO}_{3}<17 \mathrm{mmol} / \mathrm{L}$ & $6.1(1.8-21.3)$ & Chrispal et $\mathrm{al}^{21}$ \\
\hline \multirow[t]{2}{*}{ ARDS } & Bilateral pulmonary infiltrates (CXR); peak flow & & \\
\hline & ratio <200; normal CVP & $3.6(1.2-10.7)$ & \\
\hline Altered sensorium & Historical or observed altered sensorium & $3.1(1-9.9)$ & \\
\hline Shock & Systolic BP $<90 \mathrm{mmHg}$ & $3.1(I-9.8)$ & \\
\hline
\end{tabular}

Abbreviations: $\mathrm{OR}$, odds ratio; $\mathrm{Cl}$, confidence interval; $\mathrm{CNS}$, central nervous system; ARDS, acute respiratory distress syndrome; $\mathrm{CXR}$, chest $\mathrm{X}$-ray; $\mathrm{CVP}$, central venous pressure; BP, blood pressure.

Table 3 Parameters associated with adverse events in patients with scrub typhus $(P<0.0 \mathrm{I})$

\begin{tabular}{|c|c|c|c|c|c|}
\hline Patient group & Outcome & Variable/parameter & Significant value & OR $(95 \% \mathrm{CI})$ & Study \\
\hline \multirow[t]{4}{*}{ Elderly ( $>60$ years) } & Severe disease (AKI) & WBC count & $>10,000 / \mathrm{mm}^{3}$ & $2.6(1.3-5.1)$ & Jang et $\mathrm{al}^{69}$ \\
\hline & & MDRD GFR & $<60 \mathrm{~mL} / \mathrm{min}$ & $3.5(1.9-6.7)$ & \\
\hline & & Albumin & $\leq 3 \mathrm{~g} / \mathrm{dL}$ & $5(2.7-9.3)$ & \\
\hline & & APACHE II score & $>10$ points & $3.3(1.8-60.9)$ & \\
\hline \multirow[t]{2}{*}{ Adults ( $>16$ years) } & ICU admission & WBC counts & $>11,000 / \mathrm{mm}^{3}$ & $1.3(1-1.5)$ & Lee et $\mathrm{al}^{70}$ \\
\hline & & Pulmonary infiltrates & Present & $25(4-161)$ & \\
\hline Adults (>16 years) & Hospital stay $>10$ days & MODS & Two or more organs damaged & $10(2.3-43.9)$ & Lee et $\mathrm{al}^{70}$ \\
\hline Adults ( $>16$ years) & Severe scrub typhus & Rash & Present & $3.7(1.3-10.5)$ & Zhang et al $\left.\right|^{64}$ \\
\hline \multirow[t]{4}{*}{ Adults (>18 years) } & Severe scrub typhus & WBC counts & $>10,000 / \mathrm{mm}^{3}$ & $4.6(1.6-7.9)$ & Kim et $\mathrm{al}^{71}$ \\
\hline & & Serum albumin & $\leq 3 \mathrm{~g} / \mathrm{dL}$ & $8.5(1.7-14.9)$ & \\
\hline & & Age & $\geq 60$ years & $3.1(1.5-6.4)$ & \\
\hline & & Eschar & Absent & $6.6(1.2-35.8)$ & \\
\hline Adults (>18 years) & AKI & Comorbidity & Htn and/or DM and/or CKD & $6.5(2.8-15.2)$ & Sun et $\mathrm{al}^{72}$ \\
\hline Children ( $<14$ years) & MODS & AST & $>160 \mathrm{IU} / \mathrm{mL}$ & $4.7(1.4-15.6)$ & Zhao et $\mathrm{al}^{73}$ \\
\hline Not mentioned & AKI & ICU admission & - & $2.9(1.4-5.8)$ & Attur et $\mathrm{a}^{74}$ \\
\hline \multirow[t]{5}{*}{ Children and adults } & Severe scrub typhus & Pulse rate & $>100 / \mathrm{min}$ & $3.2(1.9-5.4)$ & Sriwongpan et $\mathrm{a}^{|6|}$ \\
\hline & & Crepitations & Present & $3(1.6-5.4)$ & \\
\hline & & AST & $>160 \mathrm{IU} / \mathrm{mL}$ & $2.9(1.9-4.4)$ & \\
\hline & & Serum albumin & $\leq 3 \mathrm{~g} / \mathrm{dL}$ & $4.7(3-7.5)$ & \\
\hline & & Serum creatinine & $>1.4 \mathrm{mg} / \mathrm{dL}$ & $8.2(5.1-13.4)$ & \\
\hline
\end{tabular}

Abbreviations: OR, odds ratio; $\mathrm{Cl}$, confidence interval; AKI, acute kidney injury; WBC, white blood cell; MDRD, Modification of Diet in Renal Disease; APACHE, Acute Physiology and Chronic Health Evaluation; ICU, intensive care unit; MODS, multiple-organ dysfunction syndrome; Htn, hypertension; DM, diabetes mellitus; CKD, chronic kidney disease.

was associated with fatality, presence or absence of eschars did not affect the outcome. ${ }^{65}$

\section{Laboratory diagnosis of scrub typhus}

Scrub typhus can mimic other acute febrile illnesses common in the tropics, especially when pathognomonic eschars are absent. ${ }^{10}$ Therefore, laboratory tests become mandatory for confirmation of the diagnosis. ${ }^{38,75,76}$ Methods available include direct methods like isolation of the pathogen in cell cultures (HeLa, L929, Vero, and BHK21) and detection of scrub typhus-specific DNA like $56 \mathrm{kDa}, 47 \mathrm{kDa}, 16 \mathrm{~S}$ ribosomal RNA, and GroEL gene targets by polymerase chain reaction (PCR). Indirect methods include detection of antibodies to O. tsutsugamushi by immunofluorescence assay (IFA), enzyme-linked immunosorbent assay (ELISA), ${ }^{77}$ and rapid diagnostic assays. ${ }^{78,79}$ Tables 4 and 5 give performance characteristics of the available assays for laboratory confirmation of scrub typhus.

Real-time PCR assays like the $47 \mathrm{kDa}, 56 \mathrm{kDa}$, and GroEL are increasingly used, and these detect $10-50$ copies/ $\mu \mathrm{L}$ of O. tsutsugamushi. Real-time PCR specificity is higher if type-specific genes are used (eg, $56 \mathrm{kDa}$ and $47 \mathrm{kDa}$ genes for $O$. tsutsugamushi) than if genus-specific genes are used (17 kDa genes for Rickettsia spp.), which again are stronger than nonspecific conserved "housekeeping" genes like HSPD1 (GroEL) and 16S ribosomal RNA. ${ }^{27}$ The drawback 
Table 4 Performance of nonmolecular diagnostic tests used for detection of scrub typhus

\begin{tabular}{|c|c|c|}
\hline Type of assay & Sensitivity (\%) & Specificity (\%) \\
\hline Cell culture $e^{49,81,95,96}$ & $5-56$ & 100 \\
\hline Antigen detection ${ }^{97}$ & $65-100$ & 100 \\
\hline IgM IFA $49,98-103$ & $70-100$ & $84-100$ \\
\hline $\lg M+\lg G \operatorname{IFA} A^{98,99,102}$ & $78-97$ & $98-100$ \\
\hline IgM ELISA ${ }^{29,49,76,85,89,90,98,100,101,104-106}$ & $70-100$ & $87-100$ \\
\hline IgG ELISA ${ }^{90,100,105,106}$ & $58-96$ & $92-98$ \\
\hline $\lg M \mid I_{C} 78,79,87,90,95,98$ & 47-99 & $95-100$ \\
\hline $\lg M+\lg G \quad I C T^{76,79,98,107,108}$ & $61-100$ & $74-100$ \\
\hline
\end{tabular}

Abbreviations: IFA, immunofluorescence assay; ELISA, enzyme-linked immunosorbent assay; ICT, immunochromatographic test.

of molecular assays is that the best yield is seen with eschar biopsy, followed by buffy coat, whole blood, and blood clots. ${ }^{29,38,80-82}$ As obtaining eschar biopsies is challenging, eschar-swab specimens have been used and found to be adequate for detection of scrub typhus-specific DNA. ${ }^{29,82}$ In contrast to eschar PCR, buffy-coat positivity by PCR (scrub typhus) falls to $10 \%, 4$ days after treatment. ${ }^{83}$ Sometimes, typical eschars are not observed, and in such situations PCR or immunohistochemical staining methods using eschar-like crust lesions will be useful. . $^{80,84}$

Though determination of scrub-typhus antibodies is the mainstay of scrub-typhus diagnosis ${ }^{85}$ definitive evidence of causation by serology is provided only when paired sera demonstrate a fourfold rise in titer or seroconversion. ${ }^{86} \mathrm{As}$ paired sera are seldom available, a single cutoff titer for IFA, ELISA, and rapid diagnostic tests can be used for diagnosis, provided the background noise in the population has been determined. ${ }^{76,87,88}$ Serology can determine past and recent exposure to $O$. tsutsugamushi, and thus is useful for disease surveillance. ${ }^{82}$ Though considered the gold standard, IFA is now under threat as the reference test for scrub-typhus diagnosis. ${ }^{5,7,29,49,82,88,89}$ The IFA (which uses cell culture-grown O. tsutsugamushi as antigens) can be used to differentiate IgM and IgG classes of antibodies. It is semiquantitative, as antibody concentration is reported as a titer (inverse of the highest dilution giving a positive reaction). Moreover, it requires fluorescence microscopy, is very labor-intensive, and despite adequate training of personnel is reported to have a high incidence of interassay and intra-assay variability. ${ }^{5,38,88}$ ELISA, on the other hand, can be automated and thus used to screen large numbers of sera, is objective (optical density value), economical, technically simpler, and able to detect antibody levels also. ${ }^{82}$ Due to strain variation, $56 \mathrm{kDa}$ antigen cocktails are being used for detection of scrub-typhus antibodies. ${ }^{90} \mathrm{As}$ there is evidence that ELISA is more accurate than IFA, ${ }^{48}$ it is being recommended as an alternative to the IFA..$^{88,89,91}$ Rapid diagnostic tests are becoming important, as a rapid diagnosis can be made with a certain degree of certainty, especially in endemic areas. ${ }^{79}$ The Weil-Felix agglutination test is definitely a cheap option for diagnosis of rickettsial infections, including scrub typhus, in resource-poor settings. ${ }^{76}$ Though it has poor sensitivity, it can have good specificity ${ }^{85,92}$ and is a good test in resource-poor situations for demonstrating the presence of scrub typhus or rickettsioses, though most workers feel it has poor specificity. ${ }^{76,82}$

Bayesian latent-class modeling has been used to determine diagnostic test performance, as it does not consider any test as perfect. ${ }^{49}$ In addition, composite criteria involving culture, PCR, and serological positivity like scrub typhusinfection criteria have been used. ${ }^{81}$ Moreover, a WHO case definition for scrub typhus also is available, ${ }^{93}$ as is an expert-derived Indian Council of Medical Research case definition. ${ }^{94}$ Lim et al concluded that combinations of IgM ICT and presence of eschars have good specificity and can be

Table 5 Summary of performance characteristics of molecular assays for diagnosis of scrub typhus

\begin{tabular}{|c|c|c|c|}
\hline Target & Assay & Sensitivity (\%) & Specificity (\%) \\
\hline \multirow[t]{3}{*}{$56 \mathrm{kDa}$} & Conventional PCR ${ }^{109-111}$ & $0-96$ & 100 \\
\hline & Nested PCR ${ }^{18,20,49,80,81,83,96,109,110,112-119}$ & $16-100$ & $88-100$ \\
\hline & $\mathrm{qPCR}^{120,121}$ & $65-73$ & 100 \\
\hline \multirow[t]{4}{*}{$47 \mathrm{kDa}$} & Conventional PCR ${ }^{110,111}$ & $3-7$ & 100 \\
\hline & Nested PCR ${ }^{110,11 !}$ & $81-85$ & 100 \\
\hline & $\mathrm{qPCR}^{49,81,110,122}$ & $63-81$ & $90-100$ \\
\hline & LAMPI23,* & 52 & 94 \\
\hline \multirow[t]{2}{*}{ I6S rRNA } & Conventional PCR ${ }^{111,119}$ & $45-87$ & 100 \\
\hline & qPCR 124 & 52 & 100 \\
\hline \multirow[t]{4}{*}{ GroEL } & Conventional PCR'"' & 66 & 100 \\
\hline & Nested PCR ${ }^{125}$ & 90.4 & 100 \\
\hline & qPCR ${ }^{49,81,126,127}$ & 56.4 & 96.2 \\
\hline & LAMP ${ }^{81,127}$ & 87.5 & 100 \\
\hline
\end{tabular}

Note: *An evaluation done using 24 eschar samples from scrub typhus-confirmed cases showed sensitivity and specificity of $83.3 \%$ and I00\%, respectively (Prakash, unpublished data, 20I2).

Abbreviations: qPCR, quantitative polymerase chain reaction; LAMP, loop-mediated isothermal amplification; rRNA, ribosomal RNA. 
used in resource-poor situations as point-of-care diagnostic tests, whereas performance of a PCR would be very useful in centers with facilities for same. ${ }^{49}$

\section{Coinfections and scrub typhus}

In endemic areas, coinfections have been described, and these include infections with other pathogens causing similar illness. Table 6 enumerates the grading of coinfections according to Phommasone et al, ${ }^{27}$ and Tables 7 and 8 describe such infections.

A few scenarios are described for our understanding. The first is by Sonthayanon et al, who found that among the 82 serological coinfections observed, molecular assays were positive for leptospirosis in $43(52 \%)$, scrub typhus in nine

Table 6 Grading of coinfections

\begin{tabular}{llll}
\hline Grade & Tests & Specificity & Sensitivity \\
\hline I & $\begin{array}{l}\text { Culture, NAATs, and antigen } \\
\text { detection }\end{array}$ & Best & Poor \\
II & $\begin{array}{l}\text { Seroconversion } \\
\text { Rise in titer in paired sera }\end{array}$ & Good & Good \\
& $\begin{array}{l}\text { Western blot-positive } \\
\text { Single serological value above } \\
\text { III }\end{array}$ & Poor & Very good \\
\hline
\end{tabular}

Abbreviation: NAATs, nucleic acid-amplification tests.
(11\%), and both in five (6\%), whereas $25(30 \%)$ were negative for both leptospirosis and scrub typhus. Possible explanations for the difference observed between serologic and molecular results include low sensitivity of the molecular assay, failure to test a sample obtained during the window of bacteremia in leptospirosis, serologic cross-reactivity, and acute infection caused by one pathogen in the background of a recent but inactive infection caused by the second pathogen. ${ }^{128}$

Second, in the presence of eschars, testing for Leptospira serology is unwarranted, according to Lee and Liu, as four of the seven cases who were Leptospira serology-positive had eschars. ${ }^{26}$ As treatment with doxycycline or azithromycin is very effective against Leptospira and Orientia, serological cross-reaction or coinfection does not matter, as treatment with either will be beneficial to the patient with an acute febrile illness when both serologies are positive. ${ }^{129}$

Third, dual and triple infections occur, as reported by Ahmad et al, who described malaria, dengue, and scrub typhus in five cases, 21 were dengue cross-reactive, malaria smears were positive in 14, and nine individuals had IgM antibodies to scrub typhus and dengue. Further clarification regarding which was a cross-reaction could have been determined if information regarding presence or absence of

Table 7 Coinfections (dual) demonstrated in scrub-typhus patients

\begin{tabular}{|c|c|c|c|}
\hline Evidence grade & Coinfecting pathogen (test positive) & Positive & $\begin{array}{l}\text { Diagnostic test positive } \\
\text { for scrub typhus }\end{array}$ \\
\hline \multirow[t]{7}{*}{ Grade I } & Rickettsia typhi (PCR) $^{132}$ & 3 & PCR \\
\hline & Plasmodium falciparum (smear) ${ }^{133}$ & 2 & PCR \\
\hline & Leptospira (culture, PCR, MAT) $)^{53}$ & 5 & Culture and/or PCR \\
\hline & Dengue (NSI antigen, $\mathrm{PCR})^{53}$ & 10 & \\
\hline & Rickettsia spp. (PCR) $)^{53}$ & 3 & \\
\hline & Mycoplasma pneumoniae (PCR) ${ }^{134}$ & I & PCR \\
\hline & Leptospira (PCR) $)^{128}$ & 5 & PCR \\
\hline Grade I and II & Leptospira (culture, PCR, MAT) $)^{135}$ & 4 & Culture, PCR, and IFA \\
\hline \multirow[t]{9}{*}{ Grade II } & Leptospira (culture, MAT, IFA) ${ }^{136}$ & 62 & IFA \\
\hline & Leptospira (MAT) ${ }^{26}$ & 7 & IFA \\
\hline & Leptospira (culture, MAT) ${ }^{129}$ & 11 & IFA \\
\hline & Coxiella burnetii (IFA) $)^{137}$ & 5 & IFA \\
\hline & Dengue (NSI-antigen ELISA) ${ }^{138}$ & I & IFA \\
\hline & JEV (IgM ELISA) ${ }^{53}$ & 26 & Culture and/or PCR \\
\hline & Leptospira (MAT) $)^{139}$ & 1 & IFA \\
\hline & Leptospira (MAT) $)^{140}$ & I & IFA \\
\hline & Severe fever with thrombocytopenia syndrome $(\mathrm{PCR})^{141}$ & 3 & IFA \\
\hline \multirow[t]{7}{*}{ Grade III } & Leptospira $(M A T)^{142}$ & 9 & Dot-blot assay \\
\hline & Dengue (NSI antigen) $)^{131}$ & 6 & IgM ELISA \\
\hline & Leptospira (IgM ELISA) $)^{143}$ & 8 & IgM ELISA \\
\hline & Dengue (IgM ELISA) $)^{130}$ & 21 & IgM ELISA \\
\hline & Malaria (smear) $)^{130}$ & 14 & \\
\hline & Spotted fever, group rickettsia (IFA) ${ }^{144}$ & 3 & IFA \\
\hline & R. typhi (IFA) $)^{144}$ & I & \\
\hline
\end{tabular}

Abbreviations: PCR, polymerase chain reaction; MAT, microscopic agglutination test; IFA, immunofluorescence assay; ELISA, enzyme-linked immunosorbent assay; JEV, Japanese encephalitis virus. 
Table 8 Details of infections with two other pathogens in scrub-typhus patients

\begin{tabular}{|c|c|c|c|}
\hline First pathogen (test) & Second pathogen (test) & Third pathogen (test) & Number (evidence) \\
\hline Orientia tsutsugamushi (PCR) & Rickettsia typhi (PCR) & Mycobacterium tuberculosis (culture) & I (Grade I) $)^{135}$ \\
\hline O. tsutsugamushi (PCR) & R. typhi (PCR) & Salmonella enterica, group D (culture) & I (Grade I) $)^{135}$ \\
\hline O. tsutsugamushi (PCR) & Leptospirosis (PCR) & JEV (IgM-capture ELISA) & $2(\text { Grade II) })^{53}$ \\
\hline Plasmodium vivax (RDT) & O. tsutsugamushi (PCR) & Dengue (NSI antigen) & I (Grade I) $)^{145}$ \\
\hline Malaria (smear) & Dengue (IgM ELISA) & O. tsutsugamushi (IgM ELISA) & 5 (Grade III) $^{130}$ \\
\hline O. tsutsugamushi (IFA) & R. typhi (IFA) & Spotted fever, group rickettsia (IFA) & 6 (Grade III) $^{144}$ \\
\hline
\end{tabular}

Abbreviations: PCR, polymerase chain reaction; JEV, Japanese encephalitis virus ELISA, enzyme-linked immunosorbent assay; RDT, rapid diagnostic test; IFA, immunofluorescence assay.

eschars was available ${ }^{130}$ or determination of NS1-antigen positivity, as was done by Basheer et al. ${ }^{131}$

\section{Management challenges}

Atypical clinical features and absence of eschars may result in delayed diagnosis, complications, or death. ${ }^{76}$ Scrub typhus responds promptly to effective treatment, with patients becoming afebrile within $24-48$ hours, ${ }^{41,94}$ so much so that when enteric fever, septicemia, and malaria are ruled out, empirical treatment with doxycycline (even when given late in the disease) is clinically useful. ${ }^{146}$ Therefore, empirical therapy with doxycycline is to be encouraged in regions or locales where scrub typhus is endemic or reemerging. This will lead to a reduction in complications, with a corresponding decrease in morbidity and mortality. ${ }^{146}$ Treatment for scrub typhus has been reviewed extensively by Peter et al $^{86}$ and Rajapakse et al. ${ }^{147}$ Doxycycline is useful as an empirical treatment, because of its high cost-effectiveness and wide spectrum of activity, and is considered safe in children $<8$ years of age. ${ }^{44}$ There is grade B evidence for lack of dental staining in children given short-course doxycycline, as may be given in scrub typhus. ${ }^{148-151}$ Moreover, doxycycline reaches good concentrations in cerebrospinal fluid, as does minocycline, though use of the latter is limited by dose-related vestibular side effects. ${ }^{151}$ Fluoroquinolones are not good drugs for treatment, ${ }^{150,152}$ nor are penicillins, clarithromycin, and cephalosporins. ${ }^{153} O$. tsutsugamushi with reduced susceptibility has been observed for doxycycline and chloramphenicol in Chiang Rai, northern Thailand. ${ }^{154-156}$ This may not have been true resistance, but due to delayed treatment or tolerance.

Data on scrub typhus in pregnancy are scanty. Among the 82 cases reviewed from the literature till 2014 by McGready et al, $2.5 \%$ were associated with maternal mortality. Miscarriage occurred in $17 \%$, and poor neonatal outcomes (stillbirth, preterm labor, and low birth weight) were documented in $42 \%$. Macrolide antibiotics, such as azithromycin, are safe in pregnancy, but doxycycline, which is cheaper, can also be used if the former is not available. ${ }^{157}$ The aim of therapy is to save both mother and child, ${ }^{158}$ and the benefits of therapy with doxycycline outweigh the risks. ${ }^{148-151}$ Cross et al opined that doxycycline treatment should be used in children and pregnant women for treating scrub typhus, as the infectionassociated risks are too large and thus overwhelmingly against avoiding therapy with this agent. ${ }^{151}$ Recently, Jang et al reported that intravenous azithromycin was efficacious in the treatment of severe scrub typhus. ${ }^{159}$

The major concern is that misdiagnosis occurs when the characteristic eschars are absent. ${ }^{153}$ This is of importance, as treatment with an appropriate antibiotic (doxycycline, tetracycline, or chloramphenicol) renders patients afebrile within 48 hours, such that pyrexia persisting beyond 72 hours rules out scrub typhus. Such patients have jaundice (icteric sclera and/or total bilirubin $>1.5 \mathrm{mg} / \mathrm{dL}$ ), no headache, and relative bradycardia $(<110 / \mathrm{min}){ }^{25}$

\section{Conclusion}

Scrub typhus is an important cause of febrile illness in the Asia-Pacific region. The main management challenge is institution of specific therapy in a timely and an effective manner, as stated elsewhere in this review. For this, rapid and accurate diagnosis becomes necessary, especially in the absence of eschars. In resource-poor endemic settings, clinical prediction rules have been defined and found useful. In addition, a battery of tests is needed for increasing diagnostic yield and sorting out the issue of coinfections. Finally, appropriate treatment should be initiated, keeping in mind the risk and benefits afforded by such treatment.

\section{Disclosure}

The author reports no conflicts of interest in this work.

\section{References}

1. Horton KC, Jiang J, Maina A, et al. Evidence of Rickettsia and Orientia infections among abattoir workers in Djibouti. Am J Trop Med Hyg 2016;95(2):462-465

2. Jin HS, Chu C, Han DY. Spatial distribution analysis of scrub typhus in Korea. Osong Public Health Res Perspect. 2013;4(1):4-15. 
3. Bang HA, Lee MJ, Lee WC. Comparative research on epidemiological aspects of tsutsugamushi disease (scrub typhus) between Korea and Japan. Jpn J Infect Dis. 2008;61(2):148-150.

4. Li T, Yang Z, Dong Z, Wang M. Meteorological factors and risk of scrub typhus in Guangzhou, southern China, 2006-2012. BMC Infect Dis. 2014;14:139.

5. Paris DH, Shelite TR, Day NP, Walker DH. Unresolved problems related to scrub typhus: a seriously neglected life-threatening disease. Am J Trop Med Hyg. 2013;89(2):301-307.

6. Hu J, Tan Z, Ren D, et al. Clinical characteristics and risk factors of an outbreak with scrub typhus in previously unrecognized areas, Jiangsu Province, China 2013. PLoS One. 2015;10(5):e0125999.

7. Chikeka I, Dumler JS. Neglected bacterial zoonoses. Clin Microbiol Infect. 2015;21(5):404-415.

8. Jeung YS, Kim CM, Yun NR, Kim SW, Han MA, Kim DM. Effect of latitude and seasonal variation on scrub typhus, South Korea, 2001-2013. Am J Trop Med Hyg. 2016;94(1):22-25.

9. Sundriyal D, Kumar N, Chandrasekharan A, Sharma B. Eschar: an important clue to diagnosis. BMJ Case Rep. 2013;2013:010105.

10. Kundavaram AP, Jonathan AJ, Nathaniel SD, Varghese GM. Eschar in scrub typhus: a valuable clue to the diagnosis. J Postgrad Med. 2013;59(3):177-178.

11. Park JH, Kim SJ, Youn SK, Park K, Gwack J. Epidemiology of scrub typhus and the eschars patterns in South Korea from 2008 to 2012. Jpn J Infect Dis. 2014;67(6):458-463.

12. Kweon SS, Choi JS, Lim HS, et al. A community-based case-control study of behavioral factors associated with scrub typhus during the autumn epidemic season in South Korea. Am J Trop Med Hyg. 2009;80(3):442-446.

13. Tilak R, Kunwar R, Wankhade UB, Tilak VW. Emergence of Schoengastiella ligula as the vector of scrub typhus outbreak in Darjeeling: has Leptotrombidium deliense been replaced? Indian J Public Health. 2011;55(2):92-99.

14. Lee HI, Shim SK, Song BG, et al. Detection of Orientia tsutsugamushi, the causative agent of scrub typhus, in a novel mite species, Eushoengastia koreaensis, in Korea. Vector Borne Zoonotic Dis. 2011;11(3):209-214.

15. Park GM, Shin HS. Geographical distribution and seasonal indices of chigger mites on small mammals collected on the east coast of the Republic of Korea. J Parasitol. 2016;102(2):193-198.

16. Yang LP, Liu J, Wang XJ, Ma W, Jia CX, Jiang BF. Effects of meteorological factors on scrub typhus in a temperate region of China. Epidemiol Infect. 2014;142(10):2217-2226.

17. Lee IY, Kim HC, Lee YS, et al. Geographical distribution and relative abundance of vectors of scrub typhus in the Republic of Korea. Korean J Parasitol. 2009;47(4):381-386.

18. Lee YM, Kim DM, Lee SH, Jang MS, Neupane GP. Phylogenetic analysis of the $56 \mathrm{kDa}$ protein genes of Orientia tsutsugamushi in southwest area of Korea. Am J Trop Med Hyg. 2011;84(2):250-254.

19. Varghese GM, Janardhanan J, Mahajan SK, et al. Molecular epidemiology and genetic diversity of Orientia tsutsugamushi from patients with scrub typhus in 3 regions of India. Emerg Infect Dis. 2015;21(1):64-69.

20. Ruang-Areerate T, Jeamwattanalert P, Rodkvamtook W, Richards AL, Sunyakumthorn P, Gaywee J. Genotype diversity and distribution of Orientia tsutsugamushi causing scrub typhus in Thailand. J Clin Microbiol. 2011;49(7):2584-2589.

21. Chrispal A, Boorugu H, Gopinath KG, et al. Scrub typhus: an unrecognized threat in South India - clinical profile and predictors of mortality. Trop Doct. 2010;40(3):129-133.

22. Acestor N, Cooksey R, Newton PN, et al. Mapping the aetiology of non-malarial febrile illness in Southeast Asia through a systematic review: terra incognita impairing treatment policies. PLoS One. 2012;7(9):e44269.

23. Jung HC, Chon SB, Oh WS, Lee DH, Lee HJ. Etiologies of acute undifferentiated fever and clinical prediction of scrub typhus in a non-tropical endemic area. Am JTrop Med Hyg. 2015;92(2):256-261.
24. Leelarasamee A, Chupaprawan C, Chenchittikul M, Udompanthurat S. Etiologies of acute undifferentiated febrile illness in Thailand. J Med Assoc Thai. 2004;87(5):464-472.

25. Lai $\mathrm{CH}$, Huang $\mathrm{CK}$, Weng $\mathrm{HC}$, et al. Clinical characteristics of acute $\mathrm{Q}$ fever, scrub typhus, and murine typhus with delayed defervescence despite doxycycline treatment. Am J Trop Med Hyg. 2008;79(3):441-446.

26. Lee $\mathrm{CH}$, Liu JW. Coinfection with leptospirosis and scrub typhus in Taiwanese patients. Am J Trop Med Hyg. 2007;77(3):525-527.

27. Phommasone K, Paris DH, Anantatat T, et al. Concurrent infection with murine typhus and scrub typhus in southern Laos: the mixed and the unmixed. PLoS Negl Trop Dis. 2013;7(8):e2163.

28. Chang K, Lee NY, Ko WC, et al. Identification of factors for physicians to facilitate early differential diagnosis of scrub typhus, murine typhus, and Q fever from dengue fever in Taiwan. J Microbiol Immunol Infect. 2017;50(1):104-111.

29. Paris DH, Dumler JS. State of the art of diagnosis of rickettsial diseases: the use of blood specimens for diagnosis of scrub typhus, spotted fever group rickettsiosis, and murine typhus. Curr Opin Infect Dis. 2016;29(5):433-439.

30. Tsai PJ, Yeh HC. Scrub typhus islands in the Taiwan area and the association between scrub typhus disease and forest land use and farmer population density: geographically weighted regression. BMC Infect Dis. 2013;13:191.

31. Clopton RE, Gold RE. Distribution and seasonal and diurnal activity patterns of Eutrombicula alfreddugesi (Acari: Trombiculidae) in a forest edge ecosystem. J Med Entomol. 1993;30(1):47-53.

32. Aung AK, Spelman DW, Murray RJ, Graves S. Rickettsial infections in Southeast Asia: implications for local populace and febrile returned travelers. Am J Trop Med Hyg. 2014;91(3):451-460.

33. Wu YC, Qian Q, Magalhaes RJ, et al. Spatiotemporal dynamics of scrub typhus transmission in mainland China, 2006-2014. PLoS Negl Trop Dis. 2016;10(8):e0004875.

34. Lyu Y, Tian L, Zhang L, et al. A case-control study of risk factors associated with scrub typhus infection in Beijing, China. PLoS One. 2013;8(5):e63668.

35. Wardrop NA, Kuo CC, Wang HC, Clements AC, Lee PF, Atkinson PM. Bayesian spatial modelling and the significance of agricultural land use to scrub typhus infection in Taiwan. Geospat Health. 2013;8(1):229-239.

36. Kim DM, Kim KY, Nam HS, Kweon SS, Park MY, Ryu SY. Riskfactors for human infection with Orientia tsutsugamushi: a case-control study in Korea. Clin Microbiol Infect. 2008;14(2):174-177.

37. Richards AL. Worldwide detection and identification of new and old rickettsiae and rickettsial diseases. FEMS Immunol Med Microbiol. 2012;64(1):107-10.

38. Koh GC, Maude RJ, Paris DH, Newton PN, Blacksell SD. Diagnosis of scrub typhus. Am J Trop Med Hyg. 2010;82(3):368-370.

39. Rose W, Rajan RJ, Punnen A, Ghosh U. Distribution of eschar in pediatric scrub typhus. J Trop Pediatr. 2016;62(5):415-420.

40. Kim DM, Won KJ, Park CY, et al. Distribution of eschars on the body of scrub typhus patients: a prospective study. Am J Trop Med Hyg. 2007;76(5):806-809.

41. Kaushik RM, Kaushik R, Bhargava A. Multiple eschars in scrub typhus. Trop Med Health. 2014;42(2):65-66.

42. Koraluru M, Nandigam M, Bairy I, Vidyasagar S, Varma M. Multiple eschars in scrub typhus: a case report. Trop Doct. 2017;47(1):67-69.

43. Audhya M, Abirami D, Srikanth S. Atypical eschar: an unusual cutaneous manifestation of scrub typhus. J Vector Borne Dis. 2015;52(3):267-269.

44. Jim WT, Chiu NC, Chan WT, et al. Clinical manifestations, laboratory findings and complications of pediatric scrub typhus in eastern Taiwan. Pediatr Neonatol. 2009;50(3):96-101.

45. Varghese GM, Abraham OC, Mathai D, et al. Scrub typhus among hospitalised patients with febrile illness in south India: magnitude and clinical predictors. $J$ Infect. 2006;52(1):56-60. 
46. Varghese GM, Janardhanan J, Trowbridge P, et al. Scrub typhus in south India: clinical and laboratory manifestations, genetic variability, and outcome. Int J Infect Dis. 2013;17(11):e981-e987.

47. Jeong YJ, Kim S, Wook YD, Lee JW, Kim KI, Lee SH. Scrub typhus: clinical, pathologic, and imaging findings. Radiographics. 2007;27(1):161-172.

48. Liu YX, Feng D, Suo JJ, et al. Clinical characteristics of the autumnwinter type scrub typhus cases in south of Shandong Province, northern China. BMC Infect Dis. 2009;9:82.

49. Lim C, Paris DH, Blacksell SD, et al. How to determine the accuracy of an alternative diagnostic test when it is actually better than the reference tests: a re-evaluation of diagnostic tests for scrub typhus using Bayesian LCMs. PloS One. 2015;10(5):e0114930.

50. Siddiqui MA, Khan MA, Ahmed SS, Anwar KS, Akhtaruzzaman SM, Salam MA. Recent outbreak of cutaneous anthrax in Bangladesh: clinico-demographic profile and treatment outcome of cases attended at Rajshahi Medical College Hospital. BMC Res Notes. 2012;5:464.

51. Gallagher TC, Strober BE. Cutaneous Bacillus anthracis infection. $N$ Engl J Med. 2001;345(22):1646-1647.

52. Watt G, Jongsakul K, Chouriyagune C, Paris R. Differentiating dengue virus infection from scrub typhus in Thai adults with fever. Am J Trop Med Hyg. 2003;68(5):536-538

53. Mayxay M, Castonguay-Vanier J, Chansamouth V, et al. Causes of non-malarial fever in Laos: a prospective study. Lancet Glob Health 2013;1(1):e46-e54.

54. Hamaguchi S, Cuong NC, Tra DT, et al. Clinical and epidemiological characteristics of scrub typhus and murine typhus among hospitalized patients with acute undifferentiated fever in northern Vietnam. Am J Trop Med Hyg. 2015;92(5):972-978.

55. Chrispal A, Boorugu H, Gopinath KG, et al. Acute undifferentiated febrile illness in adult hospitalized patients: the disease spectrum and diagnostic predictors: an experience from a tertiary care hospital in south India. Trop Doct. 2010;40(4):230-234.

56. Lee J, Kim DM, Yun NR, et al. A comparative study of hepatitis caused by scrub typhus and viral hepatitis A in South Korea. Am J Trop Med Hyg. 2011;85(5):873-877.

57. Liu YX, Feng D, Zhang Q, et al. Key differentiating features between scrub typhus and hemorrhagic fever with renal syndrome in northern China. Am J Trop Med Hyg. 2007;76(5):801-805.

58. Kim YS, Yun HJ, Shim SK, Koo SH, Kim SY, Kim S. A comparative trial of a single dose of azithromycin versus doxycycline for the treatment of mild scrub typhus. Clin Infect Dis. 2004;39(9): 1329-1335.

59. Chen NY, Huang PY, Leu HS, Chiang PC, Huang CT. Clinical prediction of endemic rickettsioses in northern Taiwan: relevance of peripheral blood atypical lymphocytes. J Microbiol Immunol Infect. 2008;41(5):362-368.

60. Sriwongpan P, Krittigamas P, Kantipong P, Kunyanone N, Patumanond J, Namwongprom S. Clinical indicators for severe prognosis of scrub typhus. Risk Manag Healthc Policy. 2013;6:43-49.

61. Sriwongpan P, Krittigamas P, Tantipong H, Patumanond J, Tawichasri C, Namwongprom S. Clinical risk-scoring algorithm to forecast scrub typhus severity. Risk Manag Healthc Policy. 2013;7:11-17.

62. Sriwongpan P, Patumanond J, Krittigamas P, Tantipong H, Tawichasri C, Namwongprom S. Validation of a clinical risk-scoring algorithm for severe scrub typhus. Risk Manag Healthc Policy. 2014;7: 29-34.

63. Kim DM, Yun NR, Neupane GP, et al. Differences in clinical features according to boryoung and karp genotypes of Orientia tsutsugamushi. PLoS One. 2011;6(8):e22731.

64. Zhang LY, Zhao ZT, Bi ZW, et al. Risk factors associated with severe scrub typhus in Shandong, northern China. Int J Infect Dis. 2014;29:203-207.

65. Taylor AJ, Paris DH, Newton PN. A systematic review of mortality from untreated scrub typhus (Orientia tsutsugamushi). PLoS Negl Trop Dis. 2015;9(8):e0003971.
66. Thipmontree W, Tantibhedhyangkul W, Silpasakorn S, Wongsawat E, Waywa D, Suputtamongkol Y. Scrub typhus in northeastern Thailand: eschar distribution, abnormal electrocardiographic findings, and predictors of fatal outcome. Am J Trop Med Hyg. 2016;95(4):769-773.

67. Park SW, Lee CS, Lee CK, et al. Severity predictors in eschar-positive scrub typhus and role of serum osteopontin. Am J Trop Med Hyg. 2011;85(5):924-930.

68. Varghese GM, Trowbridge P, Janardhanan J, et al. Clinical profile and improving mortality trend of scrub typhus in south India. Int J Infect Dis. 2014;23:39-43.

69. Jang MO, Kim JE, Kim UJ, et al. Differences in the clinical presentation and the frequency of complications between elderly and non-elderly scrub typhus patients. Arch Gerontol Geriatr. 2014;58(2):196-200.

70. Lee N, Ip M, Wong B, et al. Risk factors associated with life-threatening rickettsial infections. Am J Trop Med Hyg. 2008;78(6):973-978.

71. Kim DM, Kim SW, Choi SH, Yun NR. Clinical and laboratory findings associated with severe scrub typhus. BMC Infect Dis. 2010;10:108.

72. Sun IO, Kim MC, Park JW, et al. Clinical characteristics of acute kidney injury in patients with scrub typhus: RIFLE criteria validation. J Infect Chemother. 2014;20(2):93-96.

73. Zhao D, Zhang Y, Yin Z, Zhao J, Yang D, Zhou Q. Clinical predictors of multiple organ dysfunction syndromes in pediatric patients with scrub typhus. J Trop Pediatr. Epub 2016 Oct 3.

74. Attur RP, Kuppasamy S, Bairy M, et al. Acute kidney injury in scrub typhus. Clin Exp Nephrol. 2013;17(5):725-729.

75. Janardhanan J, Trowbridge P, Varghese GM. Diagnosis of scrub typhus. Expert Rev Anti Infect Ther. 2014;12(12):1533-1540.

76. Blacksell SD, Tanganuchitcharnchai A, Nawtaisong P, et al. Diagnostic accuracy of the InBios scrub typhus detect enzyme-linked immunoassay for the detection of IgM antibodies in northern Thailand. Clin Vaccine Immunol. 2016;23(2):148-154.

77. Koraluru M, Bairy I, Varma M, Vidyasagar S. Diagnostic validation of selected serological tests for detecting scrub typhus. Microbiol Immunol. 2015;59(7):371-374.

78. Lijuan Z, Si H, Yuming J, et al. A rapid, sensitive and reliable diagnostic test for scrub typhus in China. Indian J Med Microbiol. 2011;29(4):368-371.

79. Zhang L, He S, Wang S, et al. Comparison of a rapid diagnostic test and microimmunofluorescence assay for detecting antibody to Orientia tsutsugamushi in scrub typhus patients in China. Asian Pac J Trop Med. 2011;4(8):666-668.

80. Kim DM, Kim HL, Park CY, et al. Clinical usefulness of eschar polymerase chain reaction for the diagnosis of scrub typhus: a prospective study. Clin Infect Dis. 2006;43(10):1296-300.

81. Paris DH, Blacksell SD, Nawtaisong P, et al. Diagnostic accuracy of a loop-mediated isothermal PCR assay for detection of Orientia tsutsugamushi during acute scrub typhus infection. PLoS Negl Trop Dis. 2011;5(9):e1307.

82. Luce-Fedrow A, Mullins K, Kostik AP, St John HK, Jiang J, Richards AL. Strategies for detecting rickettsiae and diagnosing rickettsial diseases. Future Microbiol. 2015;10(4):537-564.

83. Kim DM, Byun JN. Effects of antibiotic treatment on the results of nested PCRs for scrub typhus. J Clin Microbiol. 2008;46(10):3465-3466

84. Lee SH, Kim DM, Cho YS, Yoon SH, Shim SK. Usefulness of eschar PCR for diagnosis of scrub typhus. J Clin Microbiol. 2006;44(3):1169-1171.

85. Prakash JA, Abraham OC, Mathai E. Evaluation of tests for serological diagnosis of scrub typhus. Trop Doct. 2006;36(4):212-213.

86. Peter JV, Sudarsan TD, Prakash JA, Varghese GM. Severe scrub typhus infection: clinical features, diagnostic challenges and management. World J Crit Care Med. 2015;4(3):244-250.

87. Kingston HW, Blacksell SD, Tanganuchitcharnchai A, et al. Comparative accuracy of the InBios scrub typhus detect IgM rapid test for the detection of IgM antibodies by using conventional serology. Clin Vaccine Immunol. 2015;22(10):1130-1132. 
88. Blacksell SD, Bryant NJ, Paris DH, Doust JA, Sakoda Y, Day NP. Scrub typhus serologic testing with the indirect immunofluorescence method as a diagnostic gold standard: a lack of consensus leads to a lot of confusion. Clin Infect Dis. 2007;44(3):391-401.

89. Blacksell SD, Lim C, Tanganuchitcharnchai A, et al. Optimal cutoff and accuracy of an IgM enzyme-linked immunosorbent assay for diagnosis of acute scrub typhus in northern Thailand: an alternative reference method to the IgM immunofluorescence assay. J Clin Microbiol. 2016;54(6):1472-1478.

90. Kim YJ, Yeo SJ, Park SJ, et al. Improvement of the diagnostic sensitivity of scrub typhus using a mixture of recombinant antigens derived from Orientia tsutsugamushi serotypes. J Korean Med Sci. 2013;28(5):672-679.

91. Dasch GA, Halle S, Bourgeois AL. Sensitive microplate enzymelinked immunosorbent assay for detection of antibodies against the scrub typhus rickettsia, Rickettsia tsutsugamushi. J Clin Microbiol. 1979;9(1):38-48.

92. Prakash JAJ, Sohan Lal T, Rosemol V, et al. Molecular detection and analysis of spotted fever group Rickettsia in patients with fever and rash at a tertiary care centre in Tamil Nadu, India. Pathog Glob Health. 2012;106(1):40-45.

93. World Health Organization. WHO Recommended Surveillance Standards. 2nd ed. Geneva: WHO; 1999.

94. Rahi M, Gupte MD, Bhargava A, Varghese GM, Arora R. DHR-ICMR guidelines for diagnosis and management of rickettsial diseases in India. Indian J Med Res. 2015;141(4):417-422.

95. Blacksell SD, Paris DH, Chierakul W, et al. Prospective evaluation of commercial antibody-based rapid tests in combination with a loopmediated isothermal amplification PCR assay for detection of Orientia tsutsugamushi during the acute phase of scrub typhus infection. Clin Vaccine Immunol. 2012;19(3):391-395.

96. Yang HH, Huang IT, Lin CH, Chen TY, Chen LK. New genotypes of Orientia tsutsugamushi isolated from humans in eastern Taiwan. PLoS One. 2012;7(10):e46997.

97. Kim DM, Park CJ, Lim SC, Park KH, Jang WJ, Lee SH. Diagnosis of scrub typhus by immunohistochemical staining of Orientia tsutsugamushi in cutaneous lesions. Am J Clin Pathol. 2008;130(4):543-551.

98. Kim YJ, Park S, Premaratna R, et al. Clinical evaluation of rapid diagnostic test kit for scrub typhus with improved performance. $J$ Korean Med Sci. 2016;31(8):1190-1196.

99. Pradutkanchana J, Silpapojakul K, Paxton H, Pradutkanchana S, Kelly DJ, Strickman D. Comparative evaluation of four serodiagnostic tests for scrub typhus in Thailand. Trans R Soc Trop Med Hyg. 1997;91(4):425-428.

100. Coleman RE, Sangkasuwan V, Suwanabun N, et al. Comparative evaluation of selected diagnostic assays for the detection of IgG and IgM antibody to Orientia tsutsugamushi in Thailand. Am J Trop Med Hyg. 2002;67(5):497-503.

101. Gupta N, Chaudhry R, Thakur CK. Determination of cutoff of ELISA and immunofluorescence assay for scrub typhus. J Glob Infect Dis. 2016;8(3):97-99.

102. Ching WM, Rowland D, Zhang Z, et al. Early diagnosis of scrub typhus with a rapid flow assay using recombinant major outer membrane protein antigen (r56) of Orientia tsutsugamushi. Clin Diagn Lab Immunol. 2001;8(2):409-414.

103. Lim C, Blacksell SD, Laongnualpanich A, et al. Optimal cutoff titers for indirect immunofluorescence assay for diagnosis of scrub typhus. J Clin Microbiol. 2015;53(11):3663-3666.

104. Rodkvamtook W, Zhang Z, Chao CC, et al. Dot-ELISA rapid test using recombinant 56-kDa protein antigens for serodiagnosis of scrub typhus. Am J Trop Med Hyg. 2015;92(5):967-971.

105. Land MV, Ching WM, Dasch GA, et al. Evaluation of a commercially available recombinant-protein enzyme-linked immunosorbent assay for detection of antibodies produced in scrub typhus rickettsial infections. J Clin Microbiol. 2000;38(7):2701-2705.

106. Suwanabun N, Chouriyagune C, Eamsila C, et al. Evaluation of an enzyme-linked immunosorbent assay in Thai scrub typhus patients. Am J Trop Med Hyg. 1997;56(1):38-43.
107. Blacksell SD, Jenjaroen K, Phetsouvanh R, et al. Accuracy of AccessBio immunoglobulin $\mathrm{M}$ and total antibody rapid immunochromatographic assays for the diagnosis of acute scrub typhus infection. Clin Vaccine Immunol. 2010;17(2):263-266.

108. Lee KD, Moon C, Oh WS, Sohn KM, Kim BN. Diagnosis of scrub typhus: introduction of the immunochromatographic test in Korea. Korean J Intern Med. 2014;29(2):253-255.

109. Janardhanan J, Prakash JAJ, Abraham OC, Varghese GM. Comparison of a conventional and nested PCR for diagnostic confirmation and genotyping of Orientia tsutsugamushi. Diagn Microbiol Infect Dis. 2014;79(1):7-9.

110. Kim DM, Park G, Kim HS, et al. Comparison of conventional, nested, and real-time quantitative PCR for diagnosis of scrub typhus. $J$ Clin Microbiol. 2011;49(2):607-612.

111. Kim CM, Cho MK, Kim DM, et al. Accuracy of conventional PCR targeting the 16S rRNA gene with the Ot-16sRF1 and Ot-16sRR1 primers for diagnosis of scrub typhus: a case-control study. $J$ Clin Microbiol. 2016;54(1):178-179.

112. Saisongkorh W, Chenchittikul M, Silpapojakul K. Evaluation of nested PCR for the diagnosis of scrub typhus among patients with acute pyrexia of unknown origin. Trans $R$ Soc Trop Med Hyg. 2004;98(6):360-366.

113. De W, Jing K, Huan Z, et al. Scrub typhus, a disease with increasing threat in Guangdong, China. PloS One. 2015;10(2):e0113968.

114. Zhang S, Song H, Liu Y, et al. Scrub typhus in previously unrecognized areas of endemicity in China. J Clin Microbiol. 2010;48(4):1241-1244.

115. Kim DM, Yun NR, Yang TY, et al. Usefulness of nested PCR for the diagnosis of scrub typhus in clinical practice: a prospective study. Am J Trop Med Hyg. 2006;75(3):542-545.

116. Manosroi J, Chutipongvivate S, Auwanit W, Manosroi A. Early diagnosis of scrub typhus in Thailand from clinical specimens by nested polymerase chain reaction. Southeast Asian JTrop Med Public Health. 2003;34(4):831-838.

117. Prakash JA, Kavitha ML, Mathai E. Nested polymerase chain reaction on blood clots for gene encoding $56 \mathrm{kDa}$ antigen and serology for the diagnosis of scrub typhus. Indian J Med Microbiol. 2011;29(1):47-50.

118. Kumar V, Kumar V, Yadav AK, et al. Scrub typhus is an under-recognized cause of acute febrile illness with acute kidney injury in India. PLoS Negl Trop Dis. 2014;8(1):e2605.

119. Sonthayanon P, Chierakul W, Wuthiekanun V, et al. Rapid diagnosis of scrub typhus in rural Thailand using polymerase chain reaction. Am J Trop Med Hyg. 2006;75(6):1099-1102.

120. Bakshi D, Singhal P, Mahajan SK, Subramaniam P, Tuteja U, Batra HV. Development of a real-time PCR assay for the diagnosis of scrub typhus cases in India and evidence of the prevalence of new genotype of O. tsutsugamushi. Acta Trop. 2007;104(1):63-71.

121. Kramme S, An LV, Khoa ND, et al. Orientia tsutsugamushi bacteremia and cytokine levels in Vietnamese scrub typhus patients. J Clin Microbiol. 2009;47(3):586-589.

122. Singhsilarak T, Leowattana W, Looareesuwan S, et al. Detection of Orientia tsutsugamushi in clinical samples by quantitative real-time polymerase chain reaction. Am J Trop Med Hyg. 2005;72(5):640-641.

123. Huber E. Loop-mediated isothermal amplification assay targeting the 47-kDa gene of Orientia tsutsugamushi: a rapid and sensitive alternative to real-time PCR. J Med Microbiol Diagn. 2012;1:4.

124. Sonthayanon P, Chierakul W, Wuthiekanun V, et al. Association of high Orientia tsutsugamushi DNA loads with disease of greater severity in adults with scrub typhus. J Clin Microbiol. 2009;47(2):430-434.

125. Li W, Dou X, Zhang L, et al. Laboratory diagnosis and genotype identification of scrub typhus from Pinggu district, Beijing, 2008 and 2010. Am J Trop Med Hyg. 2013;89(1):123-129.

126. Paris DH, Aukkanit N, Jenjaroen K, Blacksell SD, Day NP. A highly sensitive quantitative real-time PCR assay based on the GroEL gene of contemporary Thai strains of Orientia tsutsugamushi. Clin Microbiol Infect. 2009;15(5):488-495.

127. Paris DH, Blacksell SD, Newton PN, Day NP. Simple, rapid and sensitive detection of Orientia tsutsugamushi by loop-isothermal DNA amplification. Trans R Soc Trop Med Hyg. 2008;102(12):1239-1246. 
128. Sonthayanon P, Chierakul W, Wuthiekanun V, et al. Molecular confirmation of co-infection by pathogenic Leptospira spp. and Orientia tsutsugamushi in patients with acute febrile illness in Thailand. Am J Trop Med Hyg. 2013;89(4):797-799.

129. Phimda K, Hoontrakul S, Suttinont C, et al. Doxycycline versus azithromycin for treatment of leptospirosis and scrub typhus. Antimicrob Agents Chemother. 2007;51(9):3259-3263.

130. Ahmad S, Dhar M, Mittal G, et al. A comparative hospital-based observational study of mono- and co-infections of malaria, dengue virus and scrub typhus causing acute undifferentiated fever. Eur $J$ Clin Microbiol Infect Dis. 2016;35(4):705-711.

131. Basheer A, Iqbal N, Mookkappan S, et al. Clinical and laboratory characteristics of dengue-Orientia tsutsugamushi co-infection from a tertiary care center in south India. Mediterr J Hematol Infect Dis. 2016;8(1):e2016028

132. Zhang L, Li X, Zhang D, et al. Molecular epidemic survey on coprevalence of scrub typhus and marine typhus in Yuxi city, Yunnan province of China. Chin Med J (Engl). 2007;120(15):1314-1318.

133. McGready R, Ashley EA, Wuthiekanun V, et al. Arthropod borne disease: the leading cause of fever in pregnancy on the Thai-Burmese border. PLoS Negl Trop Dis. 2010;4(11):e888.

134. Lee WS, Ou TY, Chen FL, Hsu CW, Jean SS. Co-infection with Orientia tsutsugamushi and Mycoplasma pneumoniae in a traveler. J Microbiol Immunol Infect. 2015;48(1):121-122.

135. Dittrich S, Rattanavong S, Lee SJ, et al. Orientia, Rickettsia, and Leptospira pathogens as causes of CNS infections in Laos: a prospective study. Lancet Glob Health. 2015;3(2):e104-e112.

136. Suputtamongkol Y, Niwattayakul K, Suttinont C, et al. An open, randomized, controlled trial of penicillin, doxycycline, and cefotaxime for patients with severe leptospirosis. Clin Infect Dis. 2004;39(10):1417-1424.

137. Lai CH, Chen YH, Lin JN, Chang LL, Chen WF, Lin HH. Acute Q fever and scrub typhus, southern Taiwan. Emerg Infect Dis. 2009;15(10): 1659-1661.

138. Mayxay M, Sengvilaipaseuth O, Chanthongthip A, et al. Causes of fever in rural southern Laos. Am J Trop Med Hyg. 2015;93(3):517-520.

139. Wei YF, Chiu CT, Lai YF, Lai CH, Lin HH. Successful treatment of septic shock and respiratory failure due to leptospirosis and scrub typhus coinfection with penicillin, levofloxacin, and activated protein C. J Microbiol Immunol Infect. 2012;45(3):251-254.

140. Chen YS, Cheng SL, Wang HC, Yang PC. Successful treatment of pulmonary hemorrhage associated with leptospirosis and scrub typhus coinfection by early plasma exchange. J Formos Med Assoc. 2007;106(2 Suppl)):S1-S6

141. Wi YM, Woo HI, Park D, et al. Severe fever with thrombocytopenia syndrome in patients suspected of having scrub typhus. Emerg Infect Dis. 2016;22(11):1992-1995.

142. Watt G, Parola P. Scrub typhus and tropical rickettsioses. Curr Opin Infect Dis. 2003;16(5):429-436.

143. Borkakoty B, Jakharia A, Biswas D, Mahanta J. Co-infection of scrub typhus and leptospirosis in patients with pyrexia of unknown origin in Longding district of Arunachal Pradesh in 2013. Indian J Med Microbiol. 2016;34(1):88-91.
144. Kularatne SA, Edirisingha JS, Gawarammana IB, Urakami H, Chenchittikul M, Kaiho I. Emerging rickettsial infections in Sri Lanka: the pattern in the hilly Central Province. Trop Med Int Health. 2003;8(9): 803-811.

145. Kumar S, Kumar PS, Kaur G, Bhalla A, Sharma N, Varma S. Rare concurrent infection with scrub typhus, dengue and malaria in a young female. J Vector Borne Dis. 2014;51(1):71-72.

146. Premaratna R, Rajapakse RP, Chandrasena TG, et al. Contribution of rickettsioses in Sri Lankan patients with fever who responded to empirical doxycycline treatment. Trans R Soc Trop Med Hyg. 2010;104(5): 368-370.

147. Rajapakse S, Rodrigo C, Fernando SD. Drug treatment of scrub typhus. Trop Doct. 2011;41(1):1-4.

148. Boast A, Curtis N, Gwee A. Teething issues: can doxycycline be safely used in young children? Arch Dis Child. 2016;101(8):772-774.

149. Todd SR, Dahlgren FS, Traeger MS, et al. No visible dental staining in children treated with doxycycline for suspected Rocky Mountain spotted fever. J Pediatr. 2015;166(5):1246-1251.

150. Botelho-Nevers E, Rovery C, Richet H, Raoult D. Analysis of risk factors for malignant Mediterranean spotted fever indicates that fluoroquinolone treatment has a deleterious effect. JAntimicrob Chemother. 2011;66(8):1821-1830.

151. Cross R, Ling C, Day NP, McGready R, Paris DH. Revisiting doxycycline in pregnancy and early childhood: time to rebuild its reputation? Expert Opin Drug Saf. 2016;15(3):367-382.

152. Tantibhedhyangkul W, Angelakis E, Tongyoo N, et al. Intrinsic fluoroquinolone resistance in Orientia tsutsugamushi. Int J Antimicrob Agents. 2010;35(4):338-341.

153. Kurup A, Issac A, Loh JP, et al. Scrub typhus with sepsis and acute respiratory distress syndrome. J Clin Microbiol. 2013;51(8):2787-2790.

154. Watt G, Kantipong P, Jongsakul K, Watcharapichat P, Phulsuksombati D, Strickman D. Doxycycline and rifampicin for mild scrubtyphus infections in northern Thailand: a randomised trial. Lancet. 2000;356(9235):1057-1061.

155. Strickman D, Sheer T, Salata K, et al. In vitro effectiveness of azithromycin against doxycycline-resistant and -susceptible strains of Rickettsia tsutsugamushi, etiologic agent of scrub typhus. Antimicrob Agents Chemother. 1995;39(11):2406-2410.

156. Watt G, Chouriyagune C, Ruangweerayud R, et al. Scrub typhus infections poorly responsive to antibiotics in northern Thailand. Lancet. 1996;348(9020):86-89.

157. McGready R, Prakash JA, Benjamin SJ, et al. Pregnancy outcome in relation to treatment of murine typhus and scrub typhus infection: a fever cohort and a case series analysis. PLoS Negl Trop Dis. 2014;8(11):e3327.

158. Watthanaworawit W, Kolakowska E, Hanboonkunupakarn B, Ling C, McGready R. Scrub typhus infection in pregnancy: the dilemma of diagnosis and treatment in a resource-limited setting. Clin Case Rep. 2016;4(6):584-588.

159. Jang MO, Jang HC, Kim UJ, et al. Outcome of intravenous azithromycin therapy in patients with complicated scrub typhus compared with that of doxycycline therapy using propensity-matched analysis. Antimicrob Agents Chemother. 2014;58(3):1488-1493.
Research and Reports in Tropical Medicine

\section{Publish your work in this journal}

Research and Reports in Tropical Medicine is an international, peerreviewed, open access journal publishing original research, case reports, editorials, reviews and commentaries on all areas of tropical medicine, including: Diseases and medicine in tropical regions; Entomology; Epidemiology; Health economics issues; Infectious disease; Laboratory science and new technology in tropical medicine; Parasitology; Public health medicine/health care policy in tropical regions; and Microbiology. The manuscript management system is completely online and includes a very quick and fair peer-review system. Visit http://www.dovepress. com/testimonials.php to read real quotes from published authors. 